\title{
The Anatolian Clay Sealing: The First Quality Assurance System of Human History?
}

\author{
Anna Maria Ravagnan ${ }^{1}$ and Enzo Grossi ${ }^{2, *}$ \\ ${ }^{1}$ Lombardy Region Museum Office, Milano, Italy and ${ }^{2}$ Medical Director, Dipartimento Farma Italia, Bracco S.p.A, Via \\ XXV Aprile, 4, 20097 San Donato Milanese, Italy
}

\begin{abstract}
The basic philosophy of "Good Practices" and quality control in modern industry is to carefully document each step of professional activities, validating and registering interventions by different actors. One might be surprised to learn that the ancient inhabitants of Arslantepe, one of the first cities of human history, introduced clay sealing as an effective archetypal form of quality control.

At Arslantepe, a team from Rome University headed by Professor Frangipane recently found over 5,000 fragments of clay sealing or "cretulae" in the central magazines of what is considered the "palace" or type of warehouse (3300-3000 A.C.). According to the authors' hypothesis, in this environment, clay sealing was used as a form of administrative control to ensure that only authorized persons could access public stocks of goods.

Every cretula, through its seal, in which a specific symbol identified seal owner, his profession and another person, always a male, possibly his father, was a means of representing the individual who received goods, and probably it also had a value of quantity in the sense that the holder of the seal presumably always withdrew the same amount of goods. The responsible person of the warehouse, upon delivery and a count of goods to a given citizen, broke the cretula sealing the container of a given good of product. After product removal, the person who withdrew the goods closed and sealed the container again, re-affixing his own seal on a piece of moist clay. At each withdrawal, the broken cretulae were collected in appropriate containers to store them in "archives".

Controlled access to goods could therefore be guaranteed on a large scale, as jars, baskets, boxes and even doors could be sealed in the same manner.

The broken cretulae were kept by the controllers as sort of receipts, to document the withdrawal operation. These finding support the idea that authorization control of human activity has been part of our history from the beginning of civilization.
\end{abstract}

\section{INTRODUCTION}

The essence of the philosophy of Good Practices in modern industry is to carefully document each step of professional activities, whether in manufacturing, laboratory or clinical settings. This philosophy owes much to Edward Deming, who already in the 1940s had introduced the concept of quality assurance and quality control in manufacturing industry [1]. The ideas of Deming influenced regulations emerging in those years from Food and Drug Administration (FDA) as a response to pharmaceutical industry problems like that of sulfathiazole tablets that were contaminated with Phenobarbital in 1940, or thalidomide disaster owing to poor control of pharmaceutical-toxicological toxicity potential in 1960 [2]. The "good practice" philosophy in the following years has pervaded many industrial environments.

In clinical trials performed under Good Clinical Practices by pharmaceutical companies for example, special emphasis is devoted to data collection and manipulation. If clinical trial data are entered directly into a computer, there must be

*Address correspondence to this author at the Medical Director, Dipartimento Farma Italia, Bracco S.p.A, Via XXV Aprile, 4, 20097 San Donato Milanese, Italy; Tel: ++39 - 02 - 2177 2274, 348 2314339; Fax: ++39 - 02 2177 2655; E-mail: enzo.grossi@bracco.com an adequate safeguard to ensure validation, including a signed and dated print-out and back-up records. Computerized systems are validated and a detailed description for their use must be produced and kept up-to-date. All corrections to case record form and to raw data must be made in a way that does not obscure the original entry. Corrected data must be inserted with the reason for the correction (if not obvious), the date, and initials of the investigator or authorized person. For electronic data processing, only authorized persons are permitted to enter or modify data in the computer and a record is kept of these changes and deletions. If data are altered during processing, the alteration must be documented [3].

The reader might be surprised to learn that the ancient inhabitants of Arslantepe, one of the first cities of human history, introduced clay sealing as an effective archetypal form of quality control. The use and function of clay-sealing in the Prehistory and Protohistory of the ancient Near East should be reconsidered after the recent discovery of claysealing in Neolithic contexts. From the origin of state organisation, at the end of IV millennium BCE, sealing indicate a centralisation of goods and work controlled by a bureaucratic class, which also administered their redistribution. The origin of this technology is also discernible in different areas of 


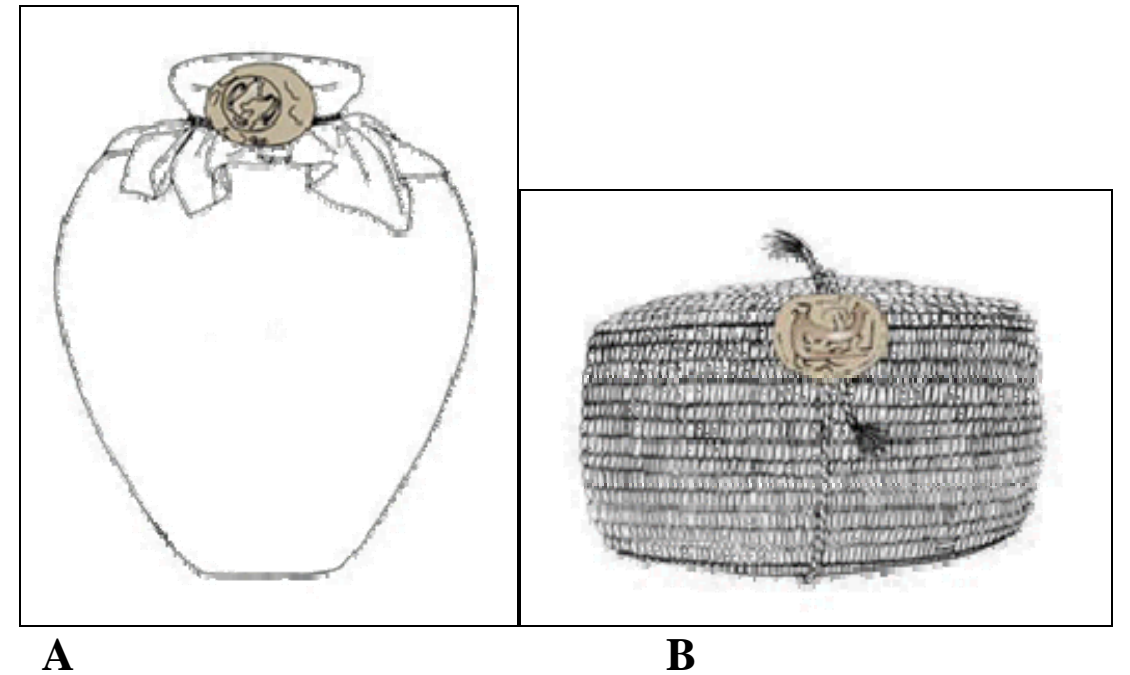

Reconstruction by Enrica Fiandra. Italian Archive of Archeologic Mission in Eastern Anatolia; Rome University "La Sapienza".

Fig. (1). Pot (A) and bag (B) locking system with the clay sealing.

the Middle East, and dates back some 8,000 years, during neolithic era, long before the invention of cuneiform writing.

\section{RESEARCH FINDINGS}

At Arslantepe, a team from Rome University headed by Professor Frangipane recently found over 5,000 fragments of clay sealing or "cretulae" in the central magazines of what is considered the "palace" or type of warehouse (3300-3000 A.C.) [4]. According to the authors' hypothesis, in this environment, clay sealing was used as a form of administrative control to ensure that only authorized persons could access public stocks of goods. Once a container such as a pot or a bag tied up with cord (Fig. 1), was closed, a piece of clay was applied to the bag and the cord. This lump, while still moist, was sealed with a special seal retainer, as a specific symbol that identified seal owner, his profession and another person, always a male, possibly his father. Cylinder seals are indisputably a southern innovation. It should be noted, however, that cylinder seals at Arslantepe were cut in a local style that may be considered an "Arslantepe" style, characterized by gauging, a curved back to the animals, and figures often depicted with three fingers or claws. Inscriptions are mostly carved in reverse, so as to leave a positive image on the clay with the figures standing out. Some are directly carved and leave a negative imprint.

In historic times, the prehistoric stamp seal was then substituted with a cylinder seal (Fig. 2).

The cylinder was rolled over wet clay to mark or identify clay tablets, envelopes, ceramics and bricks. It covered an area as large as desired, an advantage over the earlier stamp

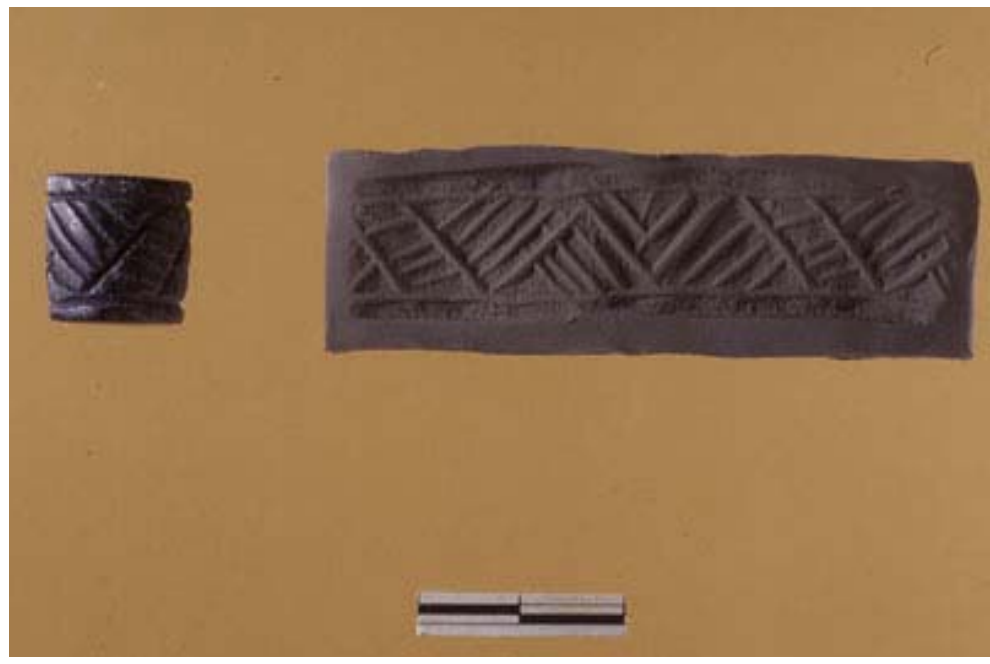

Fig. (2). Cylinder seal (http://w3.uniroma1.it/arslantepe/amministrazione.htm). 
seals. Its use and spread coincided with use of clay tablets, starting at the end of the 4th millennium and continuing to the end of the first millennium. After this time, stamp seals are used again.

Cylinder seals are important to historians. The seals were needed as signature, confirmation of receipt, or to mark clay tablets and to indicate building blocks. The invention fits with needs caused by the general development of city-states.

The control system on exits and entrances of the "palace" would have worked in this way: the responsible person of the warehouse, upon delivery and a count of goods to a given citizen, removed the cretula which in that moment sealed the container of the product that was extracted such as a bag, pithos or cowling. Once the product was removed, the container was closed and the person who withdrew the goods sealed it again, affixing his own seal. At each withdrawal, the removed or "captured" cretulae were collected in appropriate containers to store them in "archives". After their removal, cretulae lost the guarantee meaning that was maintained during the time that they sealed the goods, which assumes a new connotation of a document proving withdrawal of goods and of a receipt. Every cretula through its seal was a means of representing the individual who received goods, and probably it also had a value of quantity in the sense that the holder of the seal presumably always withdrew the same amount of goods [5].

The broken cretulae were assembled inside an archive in order to allow the responsible keeper of the warehouses of the palace to track the bookkeeping operations of which these cretulae rendered the account. Whoever secured two, five or ten alimentary grain portions or oil in a warehouse left the civil employee with a cretula that, until the next withdrawal of goods, remained applied to the cover of the container. This this cretula contained, naturally, two, five or ten prints of the seal. In this way the palace civil employee knew, through the identification of the print of seals, who was the last person to have benefited by withdrawal of food resources because the seal acted as an identity card or passport. Moreover, thanks to the number of prints in the clay seal, the civil employee knew how many food products had been secured from the person who had carried out the last operation of withdrawal of stored goods [6].
Controlled access to goods could therefore be guaranteed on a large scale, as jars, baskets, and boxes could be sealed in the same manner. A similar level of control was applied to sealing doors. The doors of magazines were usually closed with a cord wrapped around a wooden hanger, where the string was covered with a piece of clay then sealed. The person sealing the door had to be the same one who had sealed the containers, in order to avoid discovery of unauthorized access [7]. As said before, the person who was assigned to check access to stocked goods kept the broken cretulae as a receipt to document the withdrawal operation.

In conclusion, we shouldn't complain too much about authorization control in our work, since it seems that it has been part of human history from the beginning of our civilization.

\section{ACKNOWLEDGEMENTS}

The authors wish to thank Prof. Marcella Frangipane for her kind support and advice.

\section{REFERENCES}

[1] Edwards W. Deming: elementary principles of the statistical control of quality, Nippon Kagaku Gijutsu Renmei, Tokyo, 1950.

[2] John PS. The 1941 sulfathiazole disaster and the birth of good manufacturing practices. PDA J Pharm Sci Tech 1999; 53(3): 14853.

[3] Council for International Organizations of Medical Sciences. International Ethical Guidelines for Biomedical Research Involving Human Subjects. Geneva, CIOMS, 1993; Annex 1.

[4] Frangipane M, Baliossi RF, Di Nocera GM, Palmieri AM, Siracusano G. The 2001 Excavation Campaign at Zeytinli Bahçe Höyük: Preliminary Results (con Balossi RF, Di Nocera GM, Palmieri A e G. Siracusano), In: Salvage Project of the Archaeological Heritage of the Ilisu and Carchemish Dam Reservoirs. Activities in 2001, Tuna N, Greenhalg J, Velibeyoglu J, (Eds.), Middle East Technical University, Centre for Research and Assessment of the Historic Environment (TAÇDAM), Ankara 2004, 20-56

[5] Collon D. First impressions: Cylinder seals in the ancient near East, University of Chicago Press 1987.

[6] Esin, Ufuk. "The Functional Evidence of Seals," in Archives before Writing, Ferioli P, Fiandra E. (Eds.) 1994; 59-81.

[7] Rothman, Mitchell 1994a. Sealing as a Control Mechanism in Prehistory: Tepe Gawra XI, X, and VIII, in Chiefdoms and Early States in the Near East: The Organizational Dynamics of Complexity, Monographs in World Archaeology No. 18: 103-20. 